\title{
Differences in colonic tone and phasic response to a meal in the transverse and sigmoid human colon
}

\author{
M J Ford, M Camilleri, J A Wiste, R B Hanson
}

\begin{abstract}
It is not yet clear whether the regional differences in the physical properties of the colon influence its motor responses. Tonic and phasic colonic motility and compliance of the transverse and sigmoid colon were therefore assessed using a combined barostat-manometry assembly in 22 healthy subjects. Measured colonic compliance was corrected by subtraction of the compliance of the closed barostat system. The mean (SEM) preprandial colonic volumes in the transverse and sigmoid colon were similar (150 (12) and 128 (13) $\mathrm{ml}, \mathrm{p}=\mathrm{NS}$ ), corresponding to calculated mean (SEM) colonic diameters of $4.3 \mathrm{~cm}$ and $4.0 \mathrm{~cm}$ respectively. The mean increase in colonic tone postprandially was significantly greater in the transverse $(24.1 \%(3.5))$ than in the sigmoid colon $(13 \cdot 1 \%(3 \cdot 0), p<0 \cdot 01)$. The mean increase in phasic contractility was significantly greater, however, in the sigmoid than in the transverse colon (1270 (210) and 425 (60) $\mathrm{mm} \mathrm{Hg} / 90 \mathrm{~min}$ respectively, $\mathbf{p}<0 \cdot 01$ ). Compliance was greater in the transverse than sigmoid colon $(7.6(0.44)$ and 4.1 $(0.15) \mathrm{ml} / \mathrm{mm} \mathrm{Hg}, \mathrm{p}<0.001)$. The fasting volume of the colon was significantly correlated with the magnitude of the tonic response to the meal in the transverse and sigmoid colon ( $p<0.001$ for both). In conclusion, there are quantitatively different but qualitatively similar phasic and tonic responses to the meal in the two colonic regions. Differences in the viscoelastic and luminal dimensions may partly account for these differences in tonic responses.
\end{abstract}

(Gut 1995; 37: 264-269)

Keywords: colon motility, colonic compliance.

The human colon can be subdivided into two distinct regions, proximal and distal to the splenic flexure, on the basis of differing embryology, innervation, blood supply. ${ }^{1}$ The anatomical differences are also reflected by differences in the function of the proximal and distal colon. The concept of a functional division between the proximal and distal colon was proposed on the basis of differences in their luminal contents and patterns of contractile activity. ${ }^{2}$ The right colon also has a greater diameter, ${ }^{3}$ a greater absorptive ${ }^{4}{ }^{5}$ and reservoir capacity, ${ }^{56}$ and different mechanical and viscoelastic properties compared with the left colon. ${ }^{7-9}$ Furthermore, in vitro and in vivo, the circular smooth muscle of the human colon exhibits regional differences in contractile frequency, ${ }^{710}$ colonocyte absorptive function, ${ }^{11}$ myoelectrical activity, ${ }^{12}$ and responsiveness to pharmacological ${ }^{13-17}$ and physiological stimulation. ${ }^{15-18}$

Though there are numerous studies of proximal and distal colonic as well as rectal phasic motility responses to a meal, none have assessed tonic responses simultaneously in both the proximal and distal colon. Our aims, therefore, were to assess postprandial tonic and phasic responses of the healthy human colon and to consider the hypothesis that the magnitude of tonic responses in different regions is influenced primarily by the colonic compliance at each region.

\section{Methods}

\section{HEALTH VOLUNTEERS}

Twenty two healthy volunteers, aged 19-62 years $($ mean $(S E M)=31(2 \cdot 1) ; 12 \mathrm{M}$ and $10 \mathrm{~F})$, were recruited by public advertisement. None had previously undergone gastrointestinal surgery; irritable bowel syndrome, anxiety, and depressive disorders were excluded using validated, screening questionnaires, ${ }^{19} 20$ a clinical interview, and physical examination. The studies were approved by Mayo Clinic's Institutional Review Board.

\section{COLONIC MOTOR FUNCTION}

A multilumen, combined manometric and balloon assembly was placed in the prepared colon with the aid of colonoscopy and fluoroscopy. ${ }^{2122}$ Tonic and phasic contractile activity of the colon were measured by barostat balloons and conventional manometry respectively. The combined assembly comprised six manometric ports, one $10 \mathrm{~cm}$ orad to a $10 \mathrm{~cm}$ polyethylene balloon positioned in the transverse colon, one $10 \mathrm{~cm}$ abroad to a similar balloon in the sigmoid colon, and four ports, $10 \mathrm{~cm}$ apart, between the two balloons, these being $50 \mathrm{~cm}$ apart. Each balloon was tied to two metal rings incorporated in the assembly $(10 \mathrm{~cm}$ apart), and was linked to a strain gauge and an electromechanical air injection device capable of an air injection rate of $23 \mathrm{ml}$ per second. The maximum diameter of the balloons when fully distended in vitro is $7 \mathrm{~cm}$. The barostat balloons were inflated to a minimum distending pressure, defined as the pressure at which respiratory excursions were regularly recorded as changes in the barostat volume. The 'operating pressure' was set 2 $\mathrm{mm} \mathrm{Hg}$ above the minimum distending pressure (median pressure $10 \mathrm{~mm} \mathrm{Hg}$, range 
8-14 $\mathrm{mm} \mathrm{Hg}$ ). Intraballoon volumes and manometric pressure changes in response to contractile activity were monitored continuously throughout the study. The technique and its use in healthy and clinical states has previously been shown to be both safe and effective when combined with manometry. ${ }^{21-24}$

\section{COLONIC COMPLIANCE}

Colonic compliance was assessed isobarically as the volume response to ramped increments in intraballoon pressures and expressed as the slope $\mathrm{dV} / \mathrm{dP}(\mathrm{ml} / \mathrm{mm} \mathrm{Hg})$ after subtraction of the intrinsic compliance of the closed barostat system. The compliance curve of each barostat device was measured ex vivo during calibration of the instrument immediately before every study. Previous studies have confirmed that the polyethylene balloon is infinitely compliant within normal operating ranges (intraballoon volumes $<550 \mathrm{ml}$ ) and that the compliance curve of the closed system is close to linear and ranges from 5.64-5.68 $\mathrm{ml} / \mathrm{mm} \mathrm{Hg}$ for the 'Mayo' type bellows barostat pumps used in this study. The sequence of balloon distension in the proximal and distal colon was randomised and compliance curves obtained by increasing intraballoon pressure at 30 second intervals in $4 \mathrm{~mm} \mathrm{Hg}$ steps from 4 to $32 \mathrm{~mm} \mathrm{Hg}$ above 'operating pressure'.

\section{EXPERIMENTAL DESIGN}

All subjects were admitted to the General Clinical Research Center at St Marys Hospital for bowel preparation comprising 1.5-2 1 polyethylene glycol and electrolyte solution (OCL, Abbott Laboratories, Chicago, IL) on the evening before the study. All signed informed consent and women of childbearing potential had a negative plasma $\beta$ human chorionic gonadotrophin pregnancy test. After an overnight fast, colonoscopy was performed under conscious sedation with intravenous midazolam $(0.07 \mathrm{mg} / \mathrm{kg}$, Versed, Roche Laboratories, Nutley, NJ); sedation was

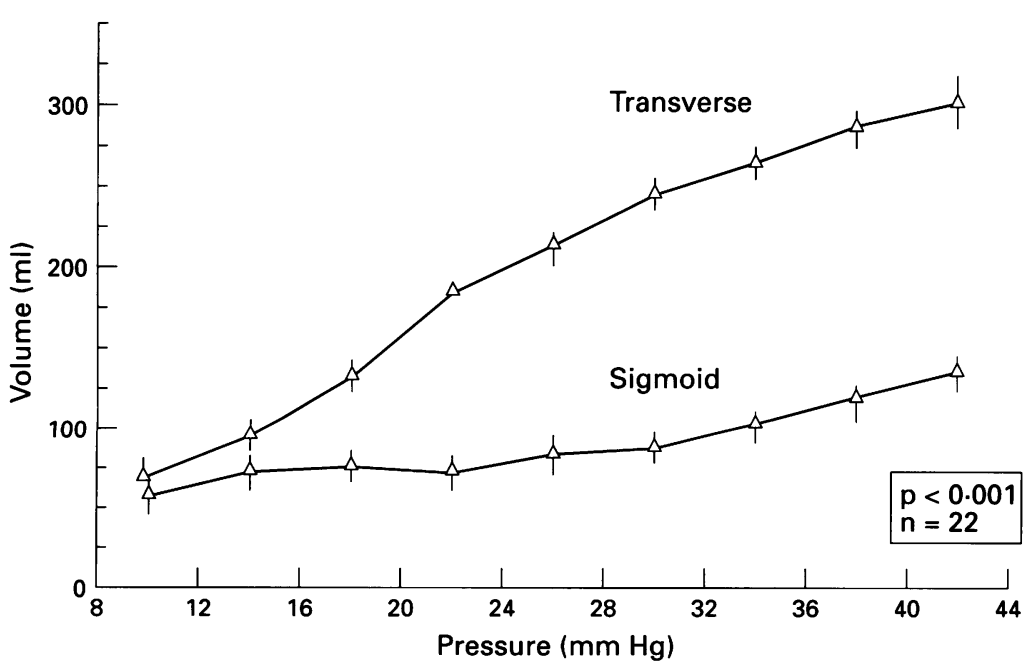

Figure 1: Regional colonic compliance in transverse and sigmoid colon, corrected for the compliance of the barostat pump. Note the greater compliance of transverse than sigmoid colon. reversed immediately after the procedure with intravenous flumazenil $\quad(0.2-0.5 \mathrm{mg}$, Romazicon, Roche Laboratories, Nutley, NJ) to ensure return to full consciousness. In the absence of any endoscopic abnormality, a 4 metre Teflon coated guidewire (Microvasive, Hobbs Medical, Stafford Springs, CT) was placed with its tip in the proximal colon and the colon deflated as the colonoscope was withdrawn. The combined manometry and balloon assembly was introduced into the colon over the guidewire and positioned under fluoroscopic control. After 60 minutes equilibration, ramp like isobaric distensions of the transverse and sigmoid colon were undertaken in a randomised sequence. Colonic tone and motility were subsequently assessed during 10 minutes before and for 90 minutes after consuming a liquid meal comprising a chocolate milkshake containing $1000 \mathrm{kcal}$ (35\% carbohydrate, 53\% fat and $12 \%$ protein).

\section{DATA ANALYSIS}

\section{Colonic motor parameters}

Phasic manometric pressure activity and changes in both pressure and volume of the two barostat balloons were sampled as analog signals at $8 \mathrm{~Hz}$ and converted to digital signals before entry into a computer. As in previous studies, movement and respiratory artifacts were filtered out using a modified VAX LAB filtering program (Digital Equipment Corporation, Boston, MA) to remove waveforms with a frequency of greater than 10 per minute, pressure changes of less than $10 \mathrm{~mm}$ $\mathrm{Hg}$ amplitude or less than four seconds duration. ${ }^{22-24}$ Phasic pressure activity was measured manometrically and expressed as the manometric activity index - that is, the area under the contraction curve per 10 minute period. The mean manometric activity index in the transverse and sigmoid colon was calculated from the mean values recorded from two sensors positioned proximal and distal to the barostat balloons. High amplitude propagated contractions (HAPCs) were defined as phasic contractions of at least $100 \mathrm{~mm} \mathrm{Hg}$ in amplitude and propagated between at least three ports (that is, for at least $20 \mathrm{~cm}$ ) at rates of $0.5-2.0 \mathrm{~cm} / \mathrm{s}^{25}$

The barostat balloon volumes recorded in the transverse and sigmoid colon were similarly computer analysed to separate baseline balloon volume from phasic volume events (PVEs). PVEs were defined as changes in volume greater than $10 \%$ of baseline volume $e^{2324}$ and occurring at the frequency of human colonic contractions previously measured using this technique - that is, 1-4 per minute. ${ }^{2122}$ Baseline volumes were calculated by computerised exclusion of the PVEs from the barostat recordings and averaged over each 10 minute period to represent colonic tone. ${ }^{23}$ Postprandial changes in colonic tone were expressed as percentage changes in barostat volumes compared with fasting to correct for interindividual variations in baseline volumes, reflecting differences in colonic diameters. ${ }^{23} 24$ 


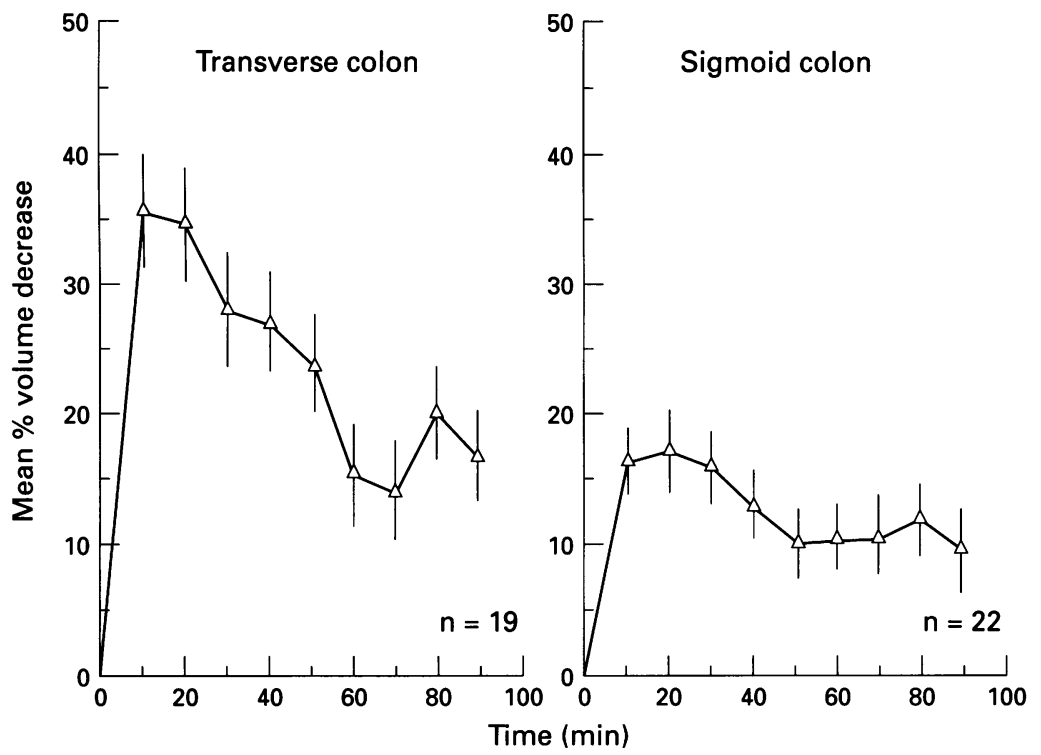

Figure 2: Regional colonic tonic response to a meal. Note the greater magnitude of the response in the transverse colon and the suggestion of a second later peak (around 80 minutes) in the tonic response, particularly in the transverse colon.

\section{Statistical analysis}

The mean (SEM) of barostat volumes during 10 minute periods before and for 90 minutes after the meal were compared by paired $t$ tests, while the paired Wilcoxon rank sum tests were used to compare manometric activity, which was not normally distributed. Colonic compliance, measured as the slope of the pressurevolume curve, was compared in the two regions by paired $t$ test. Linear regression analysis was used to estimate slope of the compliance curve, as $r^{2}$ was always $>0.95$. The influence of baseline (or preprandial) volume and compliance on the mean postprandial tonic response (mean $\Delta$ barostat volume in $\mathrm{ml}$ ) was assessed by regression analysis.

\section{Results}

FASTING COLONIC VOLUMES

Using identical barostat balloons, the mean baseline volumes of $10 \mathrm{~cm}$ segments of the transverse and sigmoid colon during the 10 minute period before the meal were not significantly different at 150 (12) and 128 (13) ml respectively. Given the cylindrical shape of the balloons, the calculated mean diameters of the colonic segments were, therefore, $4.3 \mathrm{~cm}$ and $4.0 \mathrm{~cm}$ respectively. The mean operating pressures were significantly different in the transverse and sigmoid colon at $9.8 \mathrm{~mm} \mathrm{Hg}$ $(0.3)$ and $11.4 \mathrm{~mm} \mathrm{Hg}(0.5)$ respectively $(p<0.01)$. There was a significant rank correlation between operating pressure and baseline volume in both regions of the colon (Spearman's $r=0.5, \mathrm{p}<0 \cdot 05$ ).

\section{REGIONAL COLONIC COMPLIANCE}

Figure 1 shows the comparison of the compliance curves during balloon distension of the transverse and sigmoid colon (calculated after subtraction of the volume-pressure curve of the closed barostat system). The dV/dP slope in the transverse colon was significantly greater than that of the sigmoid colon $(7 \cdot 6(0.44)$ and $4 \cdot 1(0.15) \mathrm{ml} / \mathrm{mm} \mathrm{Hg}$ respectively, $\mathrm{p}<0.001)$. There was no significant intraindividual correlation between corrected compliance curves in the transverse and sigmoid colon $(r=0 \cdot 1$, $\mathrm{p}=0 \cdot 67$ ).

REGIONAL RESPONSES TO THE MEAL

Transverse and sigmoid colonic tone and manometric activity indices increased significantly after the meal (Figs 2 and 3). These effects persisted throughout the 90 minutes after the meal. The mean postprandial reductions in barostat balloon volumes (consistent with increased colonic tone) were significantly greater in the transverse compared with the sigmoid colon $(24 \cdot 1 \%(3.5)$ and $13 \cdot 1 \%(3.0)$ respectively, $p<0.01)$. In three subjects, leaking of the proximal balloon precluded analysis of postprandial responses.

Manometric activity increased significantly in both the transverse and sigmoid colon after the meal. Mean fasting and postprandial phasic contractile activities, however, were significantly greater in the sigmoid colon compared with the transverse colon; fasting activities were 1018 (185) and $207(60) \mathrm{mm}$ $\mathrm{Hg} / 10$ min respectively, $\mathrm{p}<0.01$ ). The mean sigmoid and transverse colon postprandial phasic activities calculated over the 90 minute postprandial period were 1270 (210) and 426 (48) $\mathrm{mm} \mathrm{Hg} / 10$ min respectively $(\mathrm{p}<0 \cdot 01)$.

The pattern of both the phasic and tonic meal responses in the transverse colon differed from those seen in the sigmoid colon; the responses peaked more rapidly, often within 10 minutes of the meal, but were less sustained in the transverse colon, compared with peak response times of 20-30 minutes in the sigmoid colon. Tonic contractile responses may be bimodal with a delayed, further increase in contractility about 80 minutes after meal ingestion (Fig 2).

HAPCS

HAPCs were identified on only two occasions (once in each of two subjects) throughout a total study time of 36 hours ( $100 \mathrm{~min} \times 22$ subjects); one instance occurred in response to distension of the transverse colon during the measurement of compliance and the other, 20 minutes after the meal. Both HAPCs had amplitudes in excess of $100 \mathrm{~mm} \mathrm{Hg}$, originated in the transverse colon, and were propagated at least $40 \mathrm{~cm}$ into the sigmoid colon.

RELATION BETWEEN FASTING VOLUME, POSTPRANDIAL TONE, AND PHASIC CONTRACTIONS

Overall, there was a significant inverse relation between the fasting volume of the colonic segments evaluated and their corrected compliance $(r=-0.31, \mathrm{p}=0.05)$. This was caused by a significant inverse correlation in the transverse colon $(r=-0.87, \mathrm{p}=0.001)$, not in the sigmoid colon $(p=0 \cdot 19)$. The change in postprandial baseline volume in the barostat 


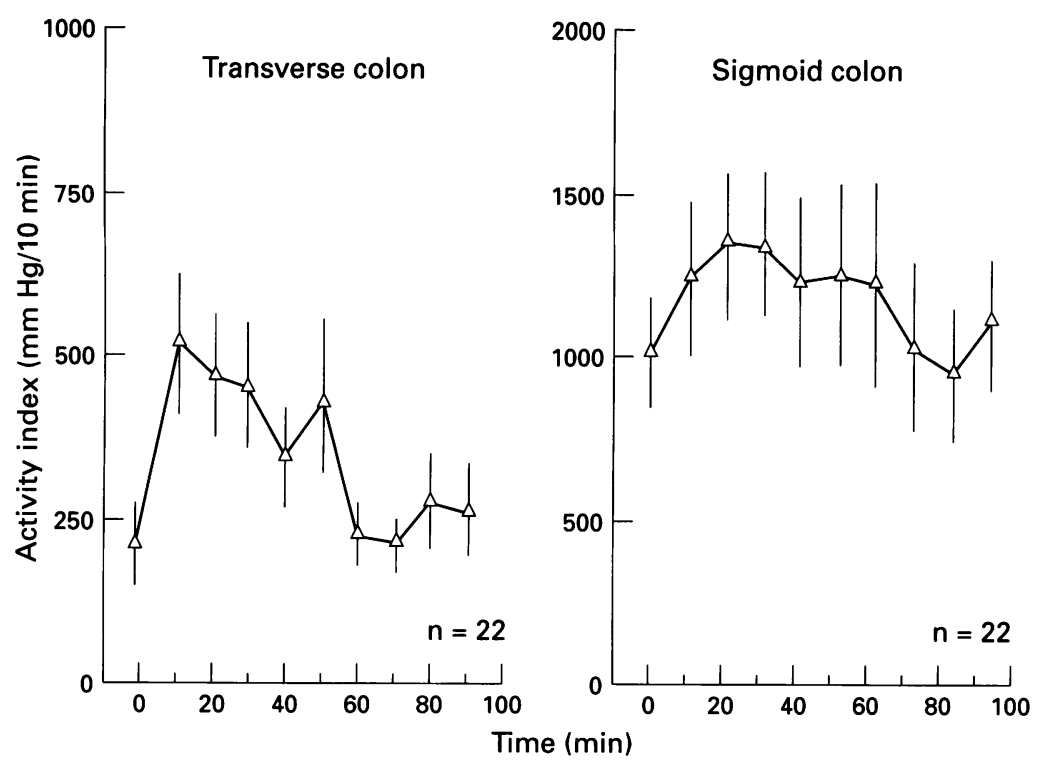

Figure 3: Regional colonic phasic response to a meal. Note the greater magnitude of the response in the sigmoid colon. balloon or tone relative to fasting was significantly related to the fasting volume or tone in both transverse $(r=0.75, \mathrm{p}<0.001)$ and sigmoid colon $(r=0.84, \mathrm{p}<0.001$, Fig 4$)$. There was no relation between postprandial phasic contractions and fasting volume (data not shown).

\section{Discussion}

The increase in colonic phasic contractile activity in response to feeding is well reported and is commonly referred to as the 'gastrocolonic reflex' ${ }^{2}$ The term is a misnomer, however, as the colonic response to food is even more noticeable in the absence of a stomach. ${ }^{26} 27$ Postprandial colonic motor activity comprises an increase in non-propulsive activity and less commonly, the occurrence of HAPCs, these being sometimes associated with 'mass movements'. ${ }^{27-30}$ As we wished to evaluate the tonic effects of a meal on two colonic regions, our experiments necessitated colonic cleansing,

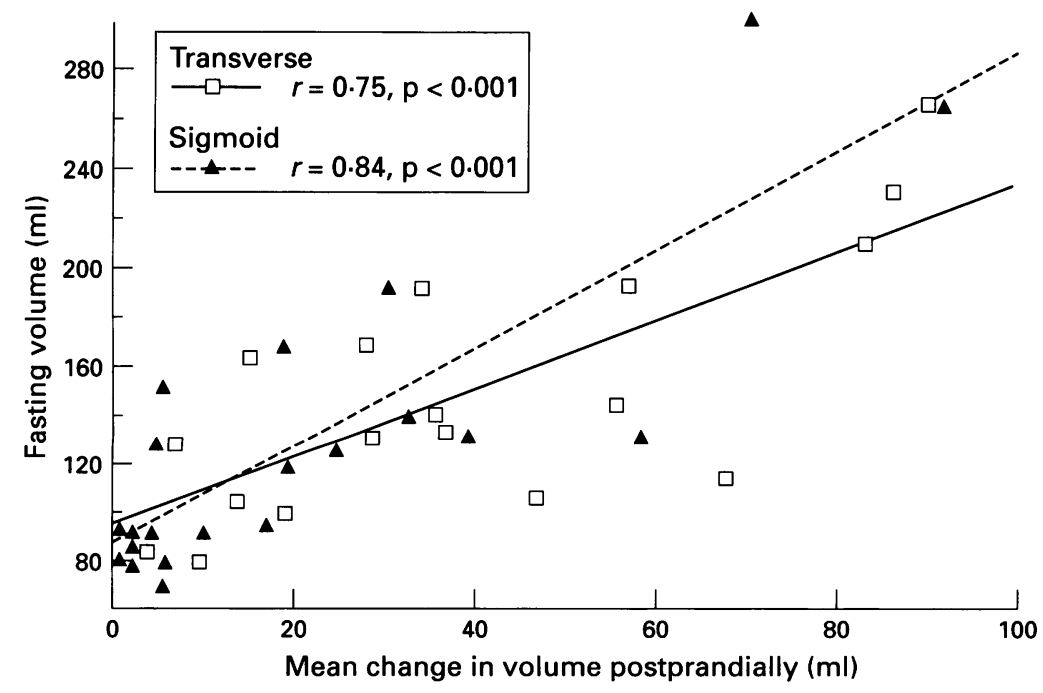

Figure 4: Relation between fasting barostat volume and postprandial change in volume (mean per 10 minute period over 90 minutes). Note the significant correlations for both sigmoid and transverse colon. and tube placement could not ethically be performed without sedation in most participants. These two factors may have conceivably changed our results. Others have shown, however, that colonic cleansing does not significantly change fasting and postprandial colonic phasic pressure activity. ${ }^{31}$ The effective half lives of midazolam and flumazenil are respectively 107 and 35 minutes, ${ }^{32}$ and hence the time to perform the procedure and equilibration period of 60 minutes should have been sufficient to minimise any drug effects on the colon's motility.

The colonic response to food includes both cephalic and intestinal phases, both of which seem to be modulated by neural and humoral mechanisms. ${ }^{33-38}$ Dietary factors, particularly the fat component of the meal, seem to exert an important influence on the motility response, especially with respect to the late phase of increased postprandial activity. ${ }^{35} 39$ Furthermore, the colonic response to feeding changes not only motor function but also sensory function; sensitivity to distension of the sigmoid colon is increased depending on the fat content of the meal, ${ }^{40}$ suggesting that changed tension in the wall of the colon may result in a change in the set point at which mechanoreceptors and visceral afferents will be stimulated.

Regional differences in the phasic motor response to food have been reported previously. $12912-1830$ Typically, the proximal colon exhibits a rapid, maximal response followed by a progressive decrease in activity and the distal colon a slower and more sustained increase in activity of considerably greater magnitude than that seen in the transverse colon.

Pharmacological stimulation of the colon with methacholine, neostigmine, and serotonin selectively enhance phasic contractility of the proximal colon alone. ${ }^{13}$ Similarly, glucagon decreases the phasic contractile and myoelectrical activities in response to a meal in the right colon but has no effect on the meal response in the left colon. ${ }^{41}$ Such findings support the concept that different mechanisms are at play in the control of the proximal and distal colon motor function but do not resolve the issue as to whether this is the result of their different neural, hormonal or mechanical properties.

We have shown that the colonic compliance and the postprandial increase in colonic tone are significantly greater in the transverse than the sigmoid colon and that in contrast, phasic motor activity is significantly greater pre and postprandially in the sigmoid colon. Our data also suggest there may be a bimodal tonic response with a second later stimulation that has previously only been reported in the canine colon $^{42}$; however, our studies were not long enough to definitively prove the presence of a second peak.

Might the observed differences in segmental motor activity be artefactual? It could be argued that these differences reflect the decreased compliance and smaller luminal diameter of the sigmoid colon, the second 
factor resulting in a proportionately greater detection of non-lumen occluding contractions. When placed in the colon, the barostat balloon tied to metal rings in a multilumen assembly assumed a cylindrical shape and conformed to the internal shape of the colon with indentations caused by haustrae. ${ }^{21}$ An approximate value for the colon's diameter can be estimated as the volume and length of the cylindrical balloon are known ( $\left.\mathrm{vol}=\pi r^{2} \mathrm{~h}\right)$. Previous studies suggested that, in the range $3.0-5.6 \mathrm{~cm}$, the luminal diameter does not change the ability of open tipped manometric techniques to detect phasic contractility. ${ }^{23} 4344$ In this study, the mean diameter in the transverse colon was $4.3 \mathrm{~cm}$ and the maximal diameter recorded was $5.8 \mathrm{~cm}$; only one subject had a transverse colon diameter $\geqslant 5.6 \mathrm{~cm}$. Thus, in regions of high compliance such as the transverse colon in health, the potential for error in detection of non-lumen occluding contractile activity was small, and the differences in luminal diameter did not influence the degree of phasic activity measured. Therefore, our phasic activity data are consistent with the previous findings of Koch et al who showed that the increase in phasic activity postprandially was sixfold in the left colon and three to fourfold in the transverse colon. ${ }^{16}$

A second potential for artefact is the entrapment of the sigmoid in the confined space of the pelvis under the pressure of overlying viscera; this may partially explain the comparatively high 'operating' pressures needed to record respiratory artefact in the sigmoid relative to the transverse colon, which is less confined by surrounding structures but is closer to the diaphragm. Using individualised 'operating' pressures for each region ensured that both regions were responsive to changes in intra-abdominal pressure in each participant and seems preferable to an empiric, standardised preset pressure. We do not believe that the significantly higher 'operating' pressure used in the sigmoid colon negates our findings as, in hollow viscera of identical compliance, the higher operating pressure would have resulted in a larger intrabag volume rather than the slightly lower preprandial volumes seen in the sigmoid colon in our study. Sigmoid entrapment may have contributed to the lower volume response to an imposed pressure or compliance and the reduced tonic responses to a physiological stimulus in the sigmoid colon in our study. Others have shown, however, that even ex vivo, the compliance of the sigmoid is less than that of the more proximal colon. ${ }^{9}$ Hence, pressure from surrounding structures is not the only reason for the lower compliance measured in the sigmoid colon, and differences in the viscoelastic properties of the sigmoid and transverse colon could at least partly explain the quantitative differences in passive compliance.

Indeed, Waldron et al have shown that the pressure increase in response to an imposed volume (that is, elastance, the reciprocal of compliance) is much greater in the descending than ascending colon, ${ }^{9}$ and in vitro studies show that human colonic muscle obtained from the proximal colon was more distensible than that from the sigmoid colon. ${ }^{7}$ These in vitro data are consistent with the greater distensibility or compliance of the transverse than the sigmoid colon, as seen in our studies. It is conceivable that differences in position in the abdomen render the transverse colon more susceptible to diaphragmatic compression and the sigmoid less compliant because of constraint by pelvic contents and bones. Thus, interpretations of resting volumes and minimum distending pressures are suspect; by way of contrast, compliance measurements, which depend on a wide spectrum of distending pressures, and estimations of the postprandial response as a proportionate change from baseline are more robust measurements.

The higher contractile frequency of human colon circular muscle strips obtained from ascending and transverse colon, compared with descending and sigmoid colon, depends on the length of muscle fibres. ${ }^{7}$ The magnitude of the tonic response to the meal is related to baseline volume in both regions, suggesting that the more relaxed the colon is, the greater is its tonic response to the meal in the two regions. Thus, physical properties partly influence the quantitative response to the meal in different regions, even if the qualitative nature of the responses is similar. Further studies are necessary to obtain a clearer understanding of the neurohumoral factors controlling regional colonic motor responses to physiological stimuli in humans. In vitro, excitatory transmitters such as substance $P$ and acetyl choline have different contractile effects on the circular muscle of proximal and distal segments of the rabbit colon. 45

The rarity with which HAPCs were seen is quite consistent with published reports; our study encompassed 36 hours of colonic pressure monitoring in 22 healthy subjects who had had prior bowel preparation, and we saw two HAPCs of $>100 \mathrm{~mm} \mathrm{Hg}$ amplitude. Soffer et $a l^{46}$ observed no more than two HAPCs per 24 hours using an ambulatory recording device with the colon unprepared. Crowell et $a l^{47}$ observed on average 6.2 HAPCs of $>75 \mathrm{~mm} \mathrm{Hg}$ per 24 hours, and $49 \%$ occurred within one hour after eating. As their subjects ate three times during a 24 hour study (total energy intake, $2500 \mathrm{kcal}$ ), our aggregate findings in a total of 36 hours associated with only one meal are consistent with the previous findings.

In any hollow viscus, muscle tone provides the active component of compliance, while the viscoelastic properties of the connective tissue and muscle fibres provide the passive component. Studies of the human colon in vivo and ex vivo show that muscle tone provides a proportionately greater contribution to total compliance in the proximal colon compared with the distal colon. ${ }^{6-8}$ There is also evidence that active compliance resulting from the muscle response requires a lesser degree of stretch or stimulation in the sigmoid colon. Thus, maximum active force generated in taenial longitudinally oriented as well as circular muscle occurred at greater length in 
ascending and transverse colon strips than with strips obtained from the descending and sigmoid colon. ${ }^{7}$

Our findings on regional colonic tone suggest a decreased ability of the distal colon to either relax to accommodate an imposed pressure load or to contract in response to stimulation by a meal, compared with the proximal colon; in contrast, the transverse colon exhibits a significantly greater dynamic range of muscle tone. The magnitude of the tonic response to the meal is significantly related to the fasting tone in both regions. The differences in passive compliance may, in part, influence the point at which tension receptors in the wall of the colon are stimulated by an imposed volume or pressure, and may explain the greater propensity for symptoms to be referred to the sigmoid region rather than the transverse colon in irritable bowel syndrome, and for the propensity for development of higher intraluminal pressures that result in the formation of diverticula in the sigmoid colon. In conclusion, although qualitatively similar, the phasic and tonic responses to a meal are quantitatively different in two colonic regions and seem to partly reflect differences in the viscoelastic properties of these two colonic regions.

We wish to thank Messrs Richard L Tucker and George $M$ Thomforde for technical support and Mrs Cindy Stanislav fo secretarial assistance.

This study was supported in part by General Clinical Research Center grant \#RR00585 from the National Institutes of Health. Dr Ford was supported by awards from the Wellington Doundation, Myre Sim Fund, and the Fulbright Commission. oundation, Myre Sim Fund, and the Fulbright Commission. This study was reported in part at the annual meeting of the and appears in abstract form in Gut 1994; 35 (suppl 5): S56.

1 Christensen J. Gross and microscopic anatomy of the large intestine. In: Phillips SF, Pemberton JH, Shorter RG, eds. The large intestine - physiology, pathophysiol
New York: Reven Press, 1991: 13-35.

2 Hertz AF, Newton A. The normal movements of the colon in man. F Physiol 1913; 47: 57-65.

3 Torsoli I, Famorino ML, Crucioli V. The relationships between anatomy and motor activity of the colon. $A m$ Dig Dis 1968; 13: 462-7.

4 Levitan R, Fordtran JS, Burrows BA, Ingelfinger FJ. Water and salt absorption in the human colon. $\mathcal{f}$ Clin Invest 1962; 41: 1754-9.

5 Devroede GJ, Phillips SF, Code CF, Lind JF. Regional differences in rates of insorption of sodium and water from 49: 1023-9.

6 Proano $M$, Camilleri $M$, Phillips SF, Brown ML Thomforde GM. Transit of solids through the human colon: regional quantification in the unprepared bowel. Am F Physiol 1990; 258: G856-62.

7 Gill RC, Cote KR, Bowes KL, Kingma YK. Human colonic smooth muscle: spontaneous contractile activity and response to stretch. Gut 1986; 27: 1006-13.

8 Snape WJ, Mayer EA, Koelbel CB, Hyman PE, Williams R Root $D$. Response of smooth muscle from proximal and distal human colon. Fournal of Gastrointestinal Motility distal human $1: 29-34$

9 Waldron DJ, Gill RC, Bowes KL. Pressure response of human colon to intraluminal distension. Dig Dis Sci 1989 34: 1163-7.

10 Kerlin P, Zinsmeister A, Phillips S. Motor responses to food in the ileum, proximal colon and distal colon in healthy humans. Gastroenterology 1983; 84: 762-70.

11 Sandle GI, Wills NK, Alles W, Binder HJ. Electrophysiology of the human colon: evidence of segmental heterogeneity. Gut 1986; 27: 999-1005.

12 Dapoigny $M$, Trolese JF, Bommelaer G, Tournut $R$. Myoelectric spiking activity of the right colon, left colon and rectosigmoid of healthy humans. Dig Dis Sci 1988 ; 33: $1007-12$.

13 Fink S, Friedman G. The differential effect of drugs on the proximal and distal colon. Am F Med 1960; 28: 534-40.

14 Burleigh DE. Motor responsiveness of proximal and distal human colonic muscle layers to acetyl choline, noradrenaline and vasoactive intestinal peptide. Dig Dis Sci 1990; 35: 617-21.

15 Misiewicz JJ, Connell AM, Pontes FA. Comparison of the effect of meals and prostigmine on the proximal and distal colon in patients with and without diarrhoea. Gut 1966; 7 468-73.

16 Koch NG, Hulten L, Leandoer L. A study of the motility in different parts of the human colon. Resting activity, response to feeding and to prostigmine. Scand Gastroenterol 1968; 3: 163-9.

17 Bassotti G, Imbimbo BP, Gaburri M, Daniotti S, Morelli A. Transverse and sigmoid colon motility in healthy humans: effects of eating and of cimetropium bromide. Digestion 1987; 37: 59-64.

18 Bassotti G, Betti C, Imbimbo BP, Pelli MA, Morelli A. Colonic motor response to eating: a manometric investigation in the proximal and distal portions of the viscus in man. Am f Gastroenterol 1989; 84: 118-22.

19 Talley NJ, Phillips SF, Wiltgen CM, Zinsmeister AR, Melton LJ. Assessment of functional gastrointestinal disease: the bowel disease questionnaire. Mayo Clin Proc 1990; 65: 1456-79.

20 Zigmond A, Snaith R. The hospital anxiety depression scale. Acta Psychiatr Scand 1983; 67: 361-70.

21 Steadman CJ, Phillips SF, Camilleri M, Haddad AC Hanson RB. Variation of muscle tone in the human colon Gastroenterology 1991; 101: 373-81

22 Steadman CJ, Phillips SF, Camilleri M, Talley NJ, Haddad A, Hanson R. Control of muscle tone in the human colon. Gut 1992; 33: 541-6.

23 von der Ohe MR, Hanson RB, Camilleri M. Comparison of simultaneous recordings of human colonic contractions by manometry and a barostat. Neurogastroenterology and Motility 1994; 6: 213-22.

24 von der Ohe M, Camilleri M, Kvols LK, Thomforde GM. Motor dysfunction of the small bowel and colon in patients with the carcinoid syndrome and diarrhea. N Engl patients with the carcinoid
$\mathfrak{7}$ Med 1993; 329: $1073-8$.

25 Bassotti G, Crowell MD, Whitehead WE. Contractile activity of the human colon: lessons from 24-hour studies. Gut 1993; 34: 129-33.

26 Holdstock DJ, Misiewicz JJ. Factors controlling colonic motility: colonic pressures and transit after meals in patients with total gastrectomy, pernicious anaemia or duodenal ulcer. Gut 1970; 11: 100-10.

27 Duthie HL. Colonic response to eating. Gastroenterology 1978; 75: 527-9.

28 Holdstock DJ, Misiewicz JJ, Smith T, Rowlands EN Propulsion (mass movements) in the human colon and its Propulsion (mass movements) in the human colon and

29 Tansy MF, Kendall FM. Experimental and clinical aspects of gastrocolic reflexes. Am F Dig Dis 1973; 18: 521-31.

30 Narducci F, Bassotti G, Gaburri M, Morelli A. Twentyfour hour manometric recording of colonic motor activity in healthy humans. Gut 1987; 28: 17-25.

31 Lémann $M$, Flourié B, Picon L, Nicolov S, Jian $R$ Rambaud JC. Is the motor activity different in the unprepared and prepared human colon? Gastroenterology 1991; 100: A463.

32 Jones RD, Chan K, Roulson CJ, Brown AG, Smith ID, Mya GH. Pharmacokinetics of flumazenil and midazolam. $\mathrm{Br} \mathscr{F}$ Anaesth 1993; 70: 286-92.

33 Rogers J, Raimundo AH, Misiewicz JJ. Cephalic phase of colonic pressure response to food. Gut 1993; 34: 537-43. 34 Harvey RF. Hormonal control of gastrointestinal motility. Am f Dig Dis 1975; 20: 523-9.

35 Snape WJ, Matarazzo SA, Cohen S. Effect of eating and gastrointestinal hormones on human colonic myoelectrical and motor activity. Gastroenterology 1978; 75: 373-8.

36 Snape WJ, Wright SH, Battle WM, Cohen S. The gastrocolic response: evidence for a neural mechanism. Gastroenterology 1979; 77: 1235-40.

37 Sun EA, Snape WJ, Cohen S, Renny A. The role of opiate receptors and cholinergic neurons in the gastrocolonic receptors and cholinergic neurons in the

38 Renny A, Snape WJ, Sun EA, London R, Cohen S. Role of cholecystokinin in the gastrocolonic response to a fat meal. Gastroenterology 1983; 85: 17-21.

39 Wright SH, Snape WJ, Battle W, Cohen S, London RI Effect of dietary components on gastrocolonic response. Am f Physiol 1980; 238: G228-32.

40 Erckenbrecht JF, Hemstege M, Ruhl A, Krause J. The sensory component of the gastrocolonic response revisited: postprandial colonic pain perception depends on meal composition. Gastroenterology 1994; 106: A494.

41 Strom JA, Condon RE, Schulte WJ, Cowles V, Go VLW. Glucagon, gastric inhibitory polypeptide and the gastrocolic response. Am 7 Surg 1982; 143: 155-9.

42 Fich A, Phillips SF, Hanson RB, Zinsmeister AR. Rapid frequency rhythmic postprandial motility in the canine ileum. Am ₹ Physiol 1989; 257: G766-72

43 von der Ohe $M$, Hanson RB, Camilleri M. Serotonergic mediation of postprandial colonic tone and phasic responses in humans. Gut 1994; 35: 536-41.

44 Daly J, Bergin A, Sun WM, Read NW. Effect of food and anti-cholinergic drugs on the pattern of rectosigmoid contractions. Gut 1993; 34: 799-802

45 Snape WJ Jr, Kim BH, Willenbucher R, Koelbel CB, Maye EA Jr, Walsh JA. Differences in the response of proximal and distal rabbit colonic muscle after electrical field stimulation. Gastroenterology 1989; 96: 321-6.

46 Soffer EE, Scalabrini P, Wingate DL. Prolonged ambulant monitoring of human colonic motility. Am f Physiol 1989; 257: G601-6.

47 Crowell MD, Bassotti G, Cheskin LJ, Schuster MM, Whitehead WE. Method for prolonged ambulatory monitoring of high-amplitude propagated contractions in the colon. Am f Physiol 1991; 261: G263-8. 